\title{
Effects of Online Course Load on Degree Completion, Transfer, and Dropout Among Community College Students of the State University of New York
}

\author{
Peter Shea \\ University at Albany, State University of New York
}

Temi Bidjerano

Furman University

\begin{abstract}
Past research suggests that some students are at risk of lower levels of academic performance when studying online compared to students who take coursework only in the classroom. Community college students appear to be among those that struggle in online settings. In this paper, we hypothesize that online course load may influence outcomes for such students, especially those at risk for lower levels of degree attainment. To examine this, we conducted a statewide study using data from the 30 community colleges $(n=45,557)$ of the State University of New York (SUNY) to understand online course-load effects on degree completion, transfer, and dropout. We conclude that when controlling for covariates known to impact degree completion, on average, community college students who successfully complete online courses nearly double their chances (odds ratio $=1.72$ ) of earning a degree or transferring to a 4-year college. However, racial minority students had reduced outcomes, and additional research is warranted.
\end{abstract}

Keywords: online learning, community college, retention, dropout, degree completion higher education

Shea, P., \& Bidjerano, T. (2019). Effects of online course load on degree completion, transfer, and dropout among community college students. Online Learning, 23(4), 6-22. doi:10.24059/olj.v23i4.1364

\section{Effects of Online Course Load on Degree Completion, Transfer, and Dropout Among SUNY Community College Students}

Postsecondary completion is a significant predictor of a host of individual and societal benefits. People with college degrees earn more, pay more taxes, and are more likely to have a job. "College education increases the chance that adults will move up the socioeconomic ladder and reduces the chance that adults will rely on public assistance" is how one study characterized the relationship (Ma, Pender, \& Welch, 2016, p. 4). Online education has increased access to valuable postsecondary credentials for millions of people (Seaman, Allen, \& Seaman, 2018). Community colleges democratize opportunities to participate in higher education through open enrollment (Mullin, 2012) and also enroll a higher proportion of online students than other institution types 
(National Center for Education Statistics [NCES], 2017). However, concerns have been voiced about outcomes for community college students who take online coursework, especially the effect of online course load on student success measures. The next section summarizes relevant literature reflecting those concerns.

\section{Review of Related Research}

Community colleges enroll a large proportion of the higher education population and also a higher percentage of students with characteristics that indicate an increased risk for dropout and other negative outcomes (Mullin, 2012). These characteristics include delayed enrollment, parttime enrollment, living in poverty, working 20 or more hours per week while in school, not having a high school diploma, having dependents, and being a single parent (NCES, 2011).

The demographics of community college students present challenges for their college completion in classrooms and may create additional challenges when they are studying in online environments. Foundational empirical research in this area by Jaggars and $\mathrm{Xu}$ (2010) and Xu and Jaggars $(2011,2013)$ found that community college students in Virginia and Washington state had higher course dropout rates and lower grades in online courses compared to classmates enrolled in face-to-face courses. These negative findings, based on comprehensive statewide data, were worse with certain subgroups: male students, younger students, Black students, and students with lower GPAs.

Aspects of this research were extended by Johnson, Cuellar Mejia, and Cook (2015) in the California Community College System. Using a sample representative of the approximately two million students in the system and similar methods, these authors also found lower course grades, higher course withdrawal, and worsening achievement gaps between majority and minority students. Furthermore, research in a large private for-profit institution supports findings related to amplification of racial achievement gaps among online community college learners (Bettinger, Fox, Loeb, \& Taylor, 2017).

In addition to course-level performance, program-level outcomes for online college students were also concerning in some large-scale investigations. Virginia and Washington state community college students who took at least one online course in their first semester were 4 to 5 percentage points less likely to return for the following semester (Jaggars \& $\mathrm{Xu}, 2010)$. Students who took a higher ratio of credits online were also less likely to earn a degree or transfer to a 4year institution than students who took a lower proportion of online credits (Xu \& Jaggars, 2011). These findings suggest that online learning reduces the upward trajectory of community college students to 4-year college settings.

On the other hand, other large-scale research suggests that students who take online courses attain degrees at higher rates than classroom-only students, despite their lower course-level performance. In both state-level (Johnson, Cuellar Mejia, \& Cook, 2015) and national studies (Shea \& Bidjerano, 2014), researchers concluded that students who took at least some online courses earned an associate's degree or transferred to a 4-year institution at higher rates than those who didn't, net of other predictors. Further, Shea and Bidjerano (2017), investigating the 30 community colleges of the SUNY system, did not replicate the finding that online study worsens achievement gaps between minority and majority students. While all students taking online courses had slightly lower grades in four of seven semesters compared to classroom courses they had taken, 
racial achievement gaps in online courses were equivalent to what they were in classroom settings. At the national level, students with some online coursework were not more likely to drop out compared to classroom-only peers (Shea \& Bidjerano, 2016).

While a variety of inconsistent findings exist regarding specific results, taken together these large-scale studies clearly identify community college students to be at risk of significantly worse outcomes online than in face-to-face settings. One consistent finding is that increasing online course load has a negative influence on academic performance. For example, in both Virginia and Washington, students who took a higher proportion of credits online were less likely to obtain a degree or transfer to a 4-year institution than students who took lower proportions of online credits (Jaggars, Edgecombe, \& Stacey, 2013). Further, among the institutions studied in the PAR framework (James, Swan, \& Daston, 2016) odds ratio analysis indicated that students mixing online and face-to-face courses or taking only face-to-face courses had up to 1.6 times greater odds of being retained than fully online students. Shea and Bidjerano (2017) found similar results for students in New York state. The odds of degree completion were about 1.5 times greater for SUNY students with a combination of online and traditional courses compared to students with classroom courses only. However, the odds of degree attainment were about 2 to 3 times lower for fully online students relative to students with a mix of online and classroom courses. Taking online courses appears to result in diminishing returns regarding the attainment of a college degree, indicating a curvilinear relationship between online course load and degree completion/transfer (Shea \& Bidjerano, 2018). Shea and Bidjerano found that on average a mix of $40 \%$ online courses to $60 \%$ classroom courses was the upper threshold for optimizing degree completion. Higher online course loads than that were associated with reduced degree completion. However, prior research has not included methodology that might account for this curvilinear relationship indicative of diminishing returns for increased online course loads. Specifically, previous research has not looked at the effects of course completion rates in online and classroom settings using survival analysis. In the next section, we discuss research questions and the analytic approach employed to address these.

\section{Purpose and Research Questions}

This current study seeks to re-investigate, using different analytic approaches, the "tipping point" at which the proportion of online course enrollment leads to impaired degree completion. Specifically this paper investigates the research questions below:

- RQ1: Using survival analysis methods, is it possible to determine a threshold for online course enrollment intensity that jeopardizes one's prospects for successful completion of a college degree and increases risk of dropout when controlling for course completion rates?

- RQ2: Does the intensity of online coursework modify the effect of traditional predictors of degree completion, such as enrollment status, remedial education, GPA, and minority status, when controlling for course completion rates?

The purpose of the study was to examine the effect of intensity of online coursework at a community college level on the probability of experiencing one of three outcomes: degree completion, transfer to a 4-year institution, and dropout. We have reasons to believe that the relationship between online education and indicators of college success is far more complex than can be adequately captured by conventional linear statistical models (Shea \& Bidjerano, 2018). Previously, we concluded that participation in online coursework has a nonlinear effect on the odds of degree, transfer, and dropout at any time of a student career. We asked also what specific factors 
explain the intricate relationships between online coursework and prospects for attaining any of the three outcomes. To extend our prior investigation, in this study we used competing-risk discrete time-event history analysis, also known as survival analysis. This method offers several advantages over traditional regression analysis. A unique feature of survival analysis is its capacity to model both the likelihood of an outcome and the timing of the outcome (Singer \& Willett, 2003) by accounting for cases for which the outcome is missing or unknown (also called censoring), thus allowing precise estimates of not only when an outcome occurs but also how it comes about. It is a flexible longitudinal method showing how processes may unfold contingent upon characteristics that remain constant and/or may change with time; that is, the method allows the incorporation of predictors of outcomes with fixed values as well as of variables that change values over time. In the context of a competing-risk discrete model, time is conceived as discrete (as opposed to continuous), and the propensity for multiple mutually exclusive outcomes is studied simultaneously. In essence, modeling revolves around estimating (a) the probability of each outcome occurring at a given time (known as risk or hazard) provided that the alternative outcomes have not occurred at a previous time and (b) the change in the risk for the outcome as a function of one or more predictors.

\section{Method}

\section{Sample}

The study used institutional data on first-time community college students enrolled in a degree program in one of the 30 community colleges that are part of the SUNY system. The data set contained archival program and course enrollment records of all students who were enrolled in a 2-year degree granting institution from fall 2012 to fall 2017. The sample used in this study $(n=$ 45,744 ) was delimited to students who had begun in an associate's degree program in fall 2012. The vast majority of the students in the sample (91.52\%) were between 16 and 25 years old, with less than $3 \%$ being older than 45 . The sample was about evenly split in terms of gender $(49.5 \%$ female). The second largest ethnic/racial group was African American (14.6\%), closely followed by Hispanic/Latino (13.9\%). More than half of the students $(58.5 \%)$ qualified for remedial coursework during their first semester, and about $62 \%$ were recipients of state or federal financial aid. The majority $(91.1 \%)$ were full-time students at the time of their first enrollment.

\section{Measures}

Time and outcome variables. We considered three competing risks: departure from a 2year institution for academic or other reasons (dropout); attainment of an educational credential; and transfer to a 4-year institution. Transfer and degree attainment were combined in one outcome variable due to some methodological considerations. In the context of competing risk survival analysis, an individual is at risk for multiple events at any given time but can experience only one of the series of events. One event cancels the risk for another event. A sizable portion of sample members had completed a degree and immediately transferred to a 4-year institution or earned their 2-year degree during their transfer semester. Had we coded these students as "degree completers" as opposed to "transfers," we would have had underestimated the hazard (probability) of transfer. Another reason for combining the two outcomes is that students are unlikely to be at risk for a degree in the first two semesters of college because associate's degrees normally take two years of full-time coursework. Had we treated degree completion as a separate outcome, we would have been unable to estimate its probability in the first two semesters. 
The available data encompassed the enrollment histories of the sample members over the course of 21 consecutive semesters, including major (spring and fall) and interim (winter and summer) terms. The last four semesters of data were used in a limited way-only as a means of identifying the subset of students who dropped out or departed (described below). The remaining 17 semesters were collapsed in the following manner:

- Time 1: fall 2012 and winter 2013;

- Time 2: spring 2013 and summer 2013;

- Time 3: fall 2013 and winter 2014;

- $\quad$ Time 4: spring 2014 and summer 2014;

- Time 5: fall 2014 and winter 2015;

- Time 6: spring 2015 and summer 2015;

- Time 7: fall 2015 and winter 2016;

- Time 8: spring 2016 and summer 2016; and

- $\quad$ Time 9: fall 2016 and winter 2017.

This resulted in nine discrete time intervals, each comprised of two consecutive semesters. This scheme was deemed unlikely to result in loss of precision, because outcomes tend to occur at the end of major terms (spring and fall), and all discrete time intervals contained a major term.

In each observation period, a student faced two distinct outcomes: the desirable outcome of graduation from their 2-year institution or transfer to a 4-year one or the negative outcome of departure or dropout from a 2-year institution. Dropout/departure functions as a competing risk to graduation or transfer and vice versa. The combined outcome degree or transfer was defined as (1) completion of a degree without evidence of subsequent return or (2) transfer to a 4-year baccalaureate program, whichever occurred first. The outcome dropout or departure was strictly defined as applicable to students who had discontinued enrollment and had never returned by the end of 2017. If the student was not enrolled in any 2017 terms and ceased enrollment in any of the semesters prior to winter 2017, they were assigned the outcome of dropout for the semester when last enrolled. If a student stopped out at any time but returned in 2017 in any capacity to a 2-year institution after one or more semesters of interrupted enrollment they were considered lost to follow-up, or "censored," as opposed to having dropped out. Thus, one censoring mechanism was gap in enrollment. Students with enrollment gaps were considered lost to follow-up because none of the events can be experienced while not being enrolled. Table 1 presents the number of censored cases by time interval.

Independent variable and covariates. The majority of students in these community colleges mixed online and classroom study. The focal variable of interest was exposure to online coursework, operationalized as online course load or the proportion of online credits attempted relative to all credits attempted in a given time interval.

We controlled for both time-dependent and time-independent covariates. These included a set of conventional predictors of college success, such as age, gender, race/ethnicity indicators (Caucasian, Asian, African American, Hispanic, and other race), international student status, level of academic preparation (whether the student qualified for remedial coursework at time of entry), student determination (whether the student had a goal to complete a degree or transfer to a 4-year institution), and type of program (humanities, STEM, or other) at exit. Age was defined as the age at baseline (fall 2012). Except for age, all time-independent variables were categorical. 
In the case of time-dependent covariates, the value of the variable changes from one period to the next, and the hazard of an event at a given time depends on the value of the covariate at that time. Time-varying covariates were selected based on both theoretical and empirical grounds; the set included number of credits earned as recorded at the end of each time interval, student status (whether the student was full-time in both terms in a time interval), end-of time-interval grade point average (GPA), and financial aid status indicators (whether a student was a federal Pell Grant recipient or a New York State Grant [TAP] recipient at a time). Student GPA and credits earned were treated as continuous variables.

\section{Data Analytic Approach}

The hazard probabilities of the two outcomes were estimated with a multinomial logistic regression as recommended in the literature (Scott \& Kennedy, 2005). Since students belonged to different programs and institutions at one time or another, and the observations were hardly ever independent of other hierarchies, our analyses accounted for the multilevel structure of the data. The clustering of students in programs and institutions at the time of exit was accounted for by specifying three-level multinomial regression models. That is, the multilevel models rested on a three-level data structure and incorporated two sources of clustering: students nested within the program they attended last, which in turn were uniquely associated with the institution where the student was last enrolled. There were 38 units at the highest level of institution and 1,491 units at the second-highest level of programs. All analyses were conducted through the GSEM routine in Stata 15.1, which provides corrections for the clustering within the highest level of hierarchy. The multilevel models were three-level random-intercept multinomial logit, in which the variances of Level 2 and Level 3 constrained to equality across outcomes.

\section{Results}

Different specifications of time were considered in the definition of the baseline hazard function. The polynomial specifications were found inadequate by virtue of statistical criteria; therefore, the more flexible general specification of time with a separate intercept for each time interval was chosen. Regression analysis was conducted sequentially.

\section{Baseline Hazard Probabilities}

The baseline hazard probabilities were obtained by fitting a multinomial logistic model including only the intercepts for the time intervals without other predictors. The baseline hazard probability of each event is given in Table 1 and illustrated in Figure 1. 
Table 1

Degree, Transfer, Departure, and Dropout Rates by Time Interval

\begin{tabular}{|c|c|c|c|c|c|c|c|c|}
\hline \multirow[t]{2}{*}{ Time } & \multirow[t]{2}{*}{$\begin{array}{l}\text { Start } \\
\text { time total }\end{array}$} & \multirow[t]{2}{*}{$\begin{array}{l}\text { Degree } \\
\text { transfer }\end{array}$} & \multirow[t]{2}{*}{$\begin{array}{l}\text { Depart } \\
\text { drop }\end{array}$} & \multirow[t]{2}{*}{$\begin{array}{l}\text { Event } \\
\text { total }\end{array}$} & \multirow[t]{2}{*}{ Censored } & \multirow[t]{2}{*}{$\begin{array}{l}\text { Cum. hazard } \\
\text { function }\end{array}$} & \multicolumn{2}{|c|}{$\begin{array}{c}\text { Model 1: } \\
\text { Baseline hazard }\end{array}$} \\
\hline & & & & & & & Deg./trans. & Depart/drop \\
\hline 1 & 45,774 & 213 & 7,539 & 7,752 & 877 & .17 & .01 & .17 \\
\hline 2 & 37,145 & 671 & 7,976 & 8,647 & 1,247 & .36 & .02 & .22 \\
\hline 3 & 27,251 & 506 & 3,247 & 3,753 & 709 & .45 & .02 & .12 \\
\hline 4 & 22,789 & 5,396 & 3,584 & 8,980 & 814 & .67 & .28 & .21 \\
\hline 5 & 12,995 & 2,574 & 1,437 & 4,011 & 394 & .77 & .22 & .14 \\
\hline 6 & 8,590 & 3,279 & 1,318 & 4,597 & 375 & .89 & .45 & .25 \\
\hline 7 & 3,618 & 352 & 894 & 1,246 & 163 & .93 & .13 & .27 \\
\hline 8 & 2,209 & 867 & 312 & 1,179 & 134 & .97 & .46 & .23 \\
\hline 9 & 896 & 62 & 240 & 302 & 594 & .98 & .09 & .29 \\
\hline
\end{tabular}

Note. Baseline hazard probabilities are significant at $\alpha=.001$.

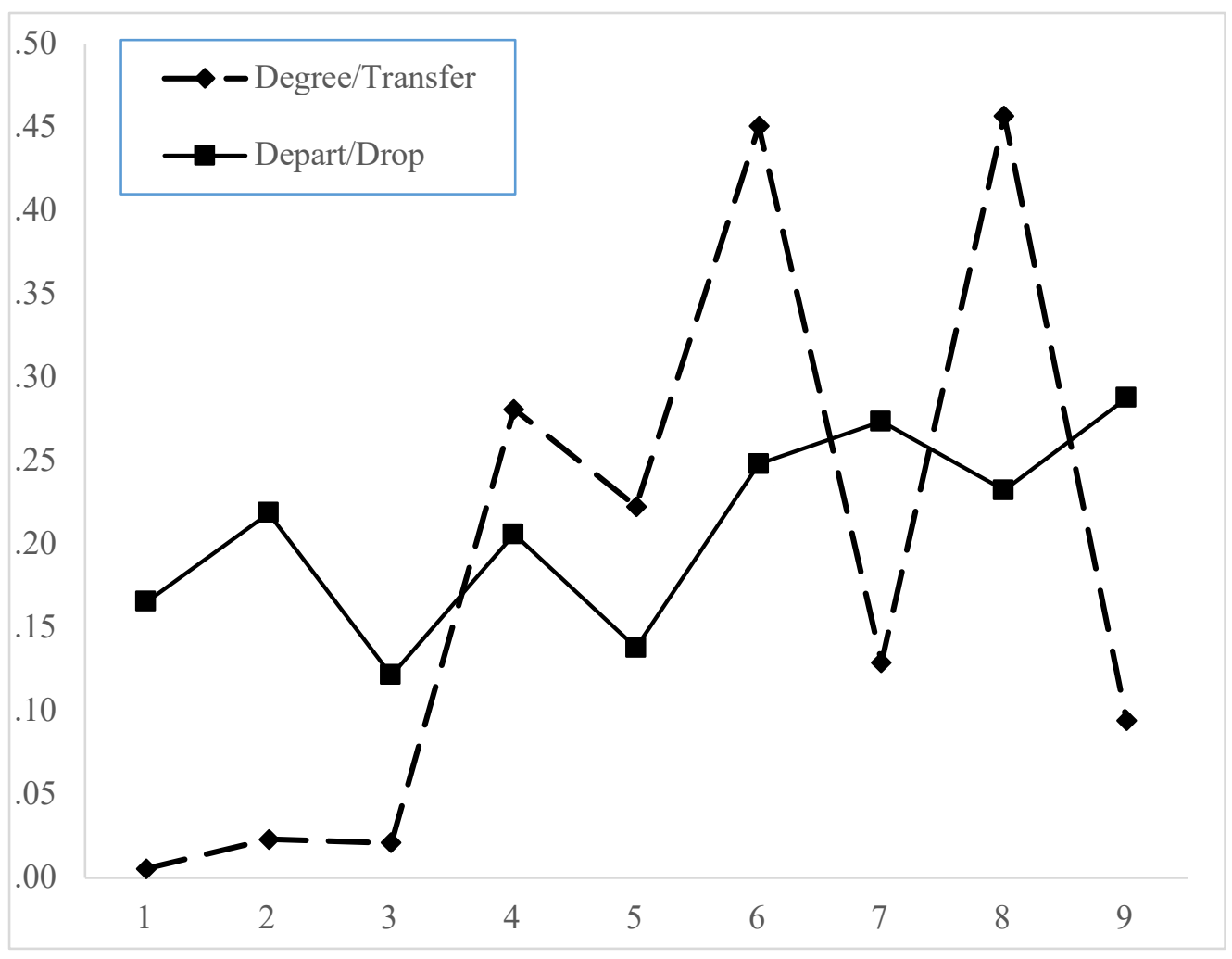

Figure 1. Hazard probability by time interval.

The unique risk (probability) associated with an outcome is also the proportion of students who experienced that particular outcome at a given time. As shown in Table 1 and Figure 1, the hazard probability for a degree and/or transfer was low at first, and then it peaked initially during 
the fourth time interval. The hazard for dropout remained relatively constant across time. The plots suggest also that events (of any kind) tended to occur mostly in the spring and summer terms. The corresponding cumulative functions are profiled in Figure 2.

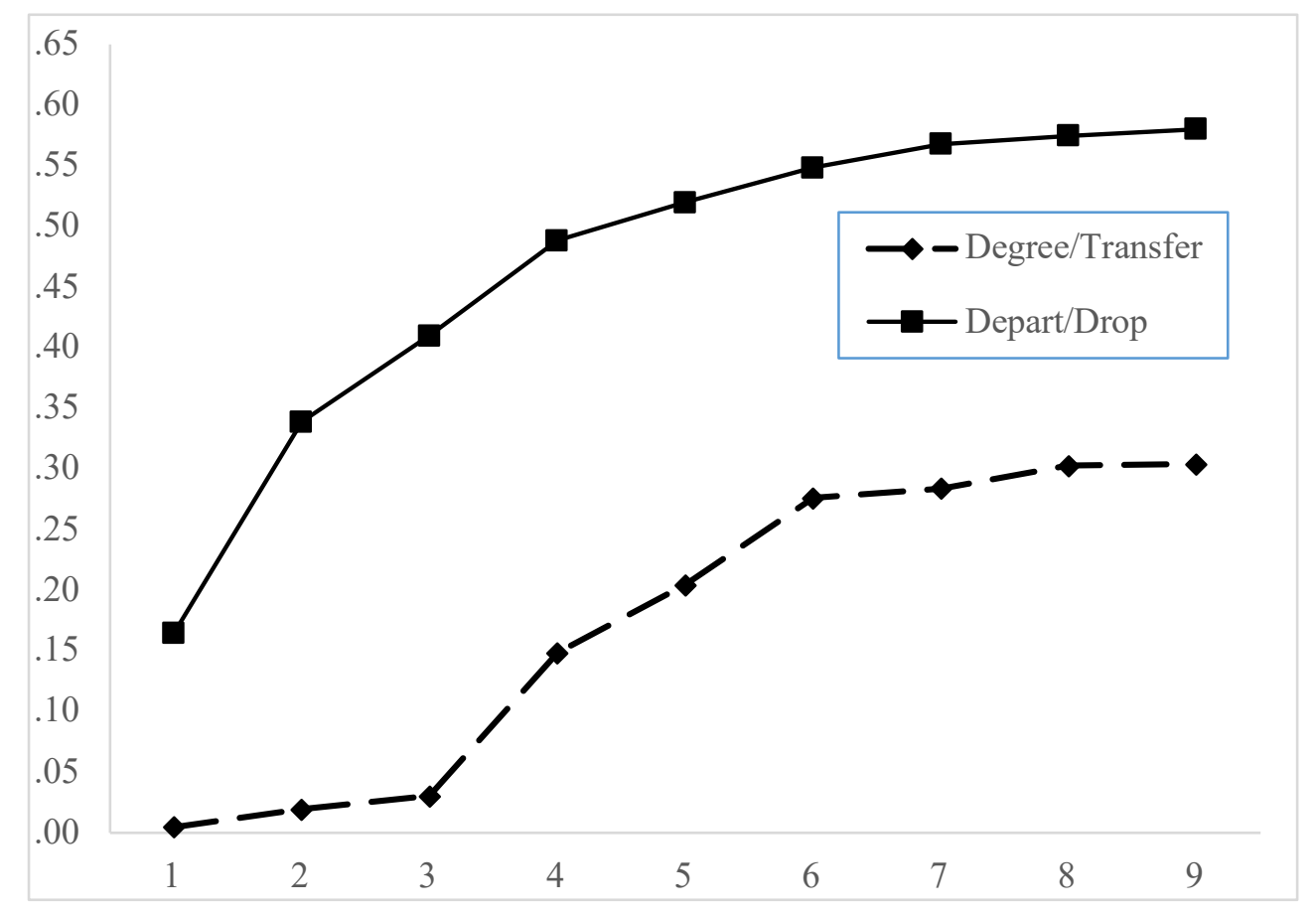

Figure 2. Cumulative hazard probability by time interval.

The cumulative hazard represents event rates or the cumulative proportions of students with an event up to a particular time interval. The cumulative hazard probability of degree/transfer increased slowly in the first terms when the hazard was low, and then it increased steadily. With respect to departure/dropout, the probability increased more rapidly in the first 2 years of college. In both cases, there was little change in the cumulative hazard probabilities after the third year in college. The median time to transfer or degree was 3 years, whereas the median time-to-dropout or departure was found to be 2 years. Overall, by the end of the second year of college, $50 \%$ of the sample members had experienced one outcome or another.

\section{The Effect of Semester Online Course Load}

The addition of course load, with its square term as a predictor, resulted in substantial improvement in model fit, as evidenced by a drop in the deviance statistics. The effect of load varied depending upon outcome. Students who opted for more online courses at any given time had a higher conditional probability of degree or transfer, but benefits wore off at higher levels of online course intensity (see Figure 3). 


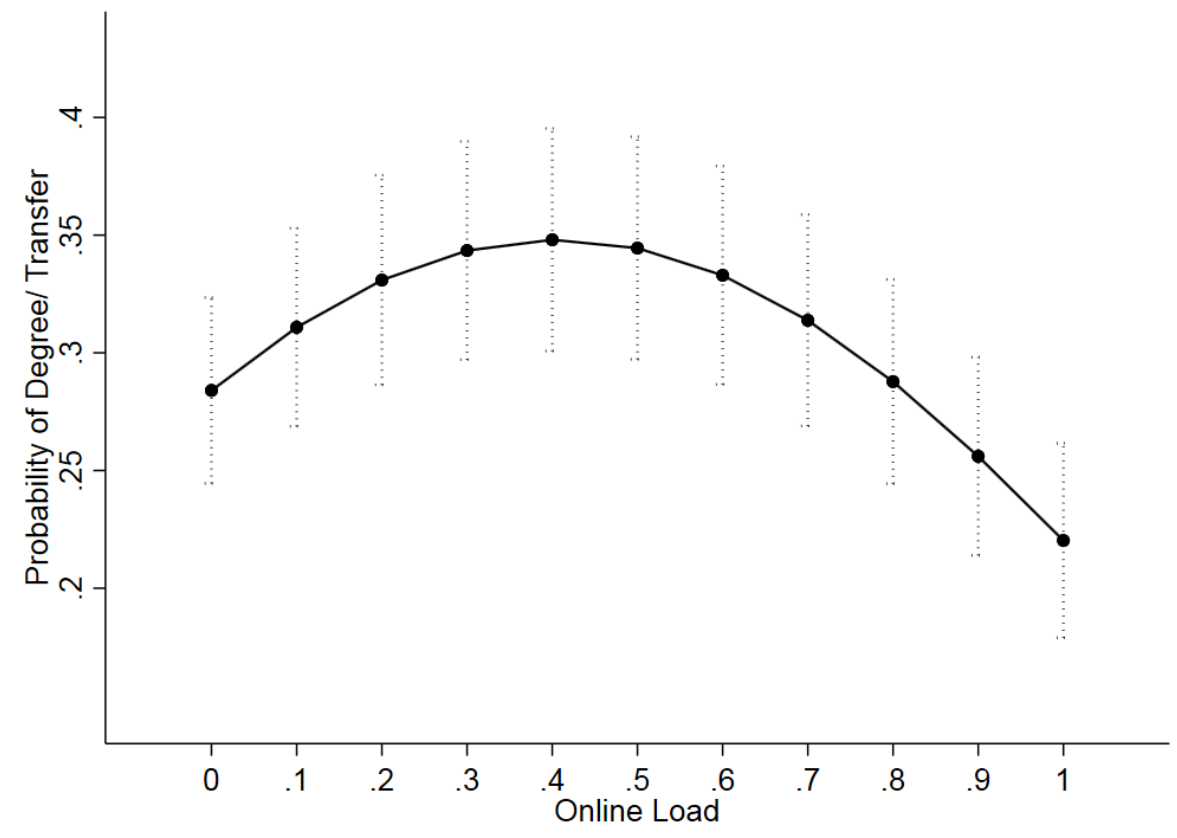

Figure 3. Probability of degree/transfer at Time 4 by online load.

Conversely, increasing levels of online load at first decreased the hazard of dropping out in any given term, but this trend eventually reversed, and at a certain point each additional credit began to increase risk of dropping out (see Figure 4).

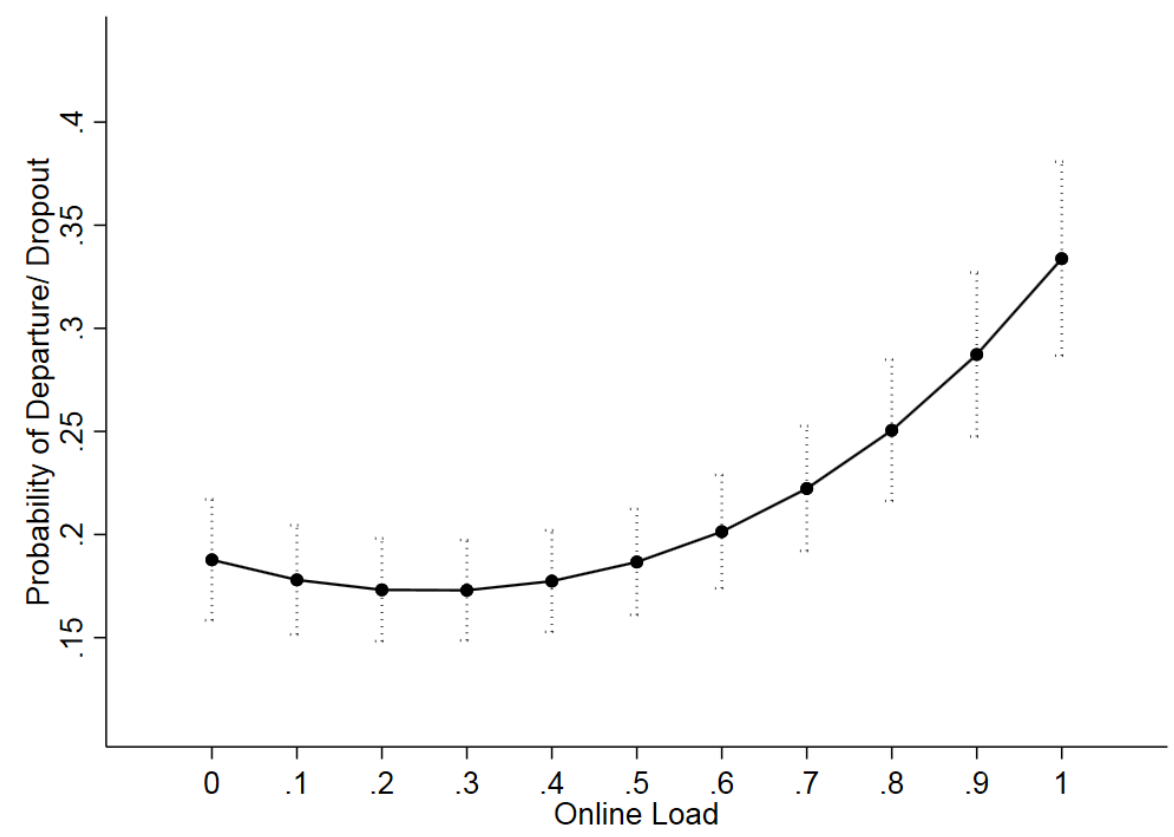

Figure 4. Probability of departure/dropout at Time 4 by online load. 
The hazard associated with online course load was found to be invariant across time intervals. Contrary to previous research, our results suggest that effect of the intensity of the effect of online coursework on probability of dropping out is not linear in nature.

\section{Covariate Effects and the Relationship Between Online Load and Outcomes}

With the last set of models shown in Table 2, we addressed the question of whether the effect of online load changed in the presence of other well-known predictors of college success. Our analysis indicated that effect of online load remained notable after controlling for a host of traditional indicators of degree completion, transfer, and dropout. Conventional demographic predictors of college success behaved in predicable fashion when the time-varying predictors of semester GPA and online coursework were not considered (see Model 3 in Table 2).

Table 2

Results From Multilevel Multinomial Logistic Regression: Time to Degree/Transfer and Time to Departure/Dropout

\begin{tabular}{|c|c|c|c|c|c|c|c|c|c|c|c|c|c|c|c|c|}
\hline \multirow[t]{3}{*}{ Predictors } & \multicolumn{4}{|c|}{ Model 2} & \multicolumn{4}{|c|}{ Model 3} & \multicolumn{4}{|c|}{ Model 4} & \multicolumn{4}{|c|}{ Model 5} \\
\hline & \multicolumn{2}{|l|}{$\mathrm{Deg} / \mathrm{Tr}$} & \multicolumn{2}{|l|}{ Depart } & \multicolumn{2}{|l|}{$\mathrm{Deg} / \mathrm{Tr}$} & \multicolumn{2}{|l|}{ Depart } & \multicolumn{2}{|l|}{$\mathrm{Deg} / \mathrm{Tr}$} & \multicolumn{2}{|l|}{ Depart } & \multicolumn{2}{|l|}{$\mathrm{Deg} / \mathrm{Tr}$} & \multicolumn{2}{|l|}{ Depart } \\
\hline & Est & OR & Est & OR & Est & OR & Est & OR & Est & OR & Est & OR & Est & OR & Est & OR \\
\hline On & $1.44^{* * *}$ & 4.20 & $-.86^{* * *}$ & .42 & $1.08^{* * *}$ & 2.95 & $-.53^{* * *}$ & .59 & $1.35^{* * *}$ & 3.85 & $-.47^{* * *}$ & .63 & $.54^{* *}$ & 1.72 & .00 & 1.00 \\
\hline On2 & $-1.65^{* * *}$ & .19 & $1.65^{* * *}$ & 5.2 & $-1.25^{* * *}$ & .29 & $1.27^{* * *}$ & 3.56 & $-1.35^{* * *}$ & .26 & $.71^{* * *}$ & 2.04 & -.23 & .79 & .06 & 1.06 \\
\hline Age & & & & & $-.10^{* * *}$ & .91 & $.09^{* * *}$ & 1.09 & $-.15^{* * *}$ & .86 & $.15^{* * *}$ & 1.16 & $-.15^{* * *}$ & .86 & $.11^{* * *}$ & 1.12 \\
\hline Age2 & & & & & $.00^{* * *}$ & 1.00 & $-.00^{* * *}$ & 1.00 & $.00^{* * *}$ & 1.00 & $.00^{* * * *}$ & 1.00 & $.00^{* * *}$ & 1.00 & $.00^{* * *}$ & 1.00 \\
\hline Female & & & & & $.07^{* * *}$ & 1.07 & $-.27^{* * *}$ & .76 & $-.05^{*}$ & .95 & $-.08^{* * *}$ & .92 & -.05 & .95 & $-.10^{* * *}$ & .90 \\
\hline Asian & & & & & $-.14^{* *}$ & .87 & $-.28^{* * *}$ & .75 & -.15 & .86 & $-.30^{* * *}$ & .74 & -.18 & .84 & $-.31^{* * *}$ & .74 \\
\hline Black & & & & & $-.27^{* * *}$ & .77 & $.34^{* * *}$ & 1.40 & -.08 & .92 & .01 & 1.01 & $-.10^{*}$ & .91 & .01 & 1.01 \\
\hline Hisp & & & & & $-.28^{* * *}$ & .76 & $.17^{* * *}$ & 1.19 & $-.25^{* * *}$ & .78 & .02 & 1.02 & $-.22^{* * *}$ & .80 & -.01 & .99 \\
\hline Rc_oth & & & & & $-.24^{* *}$ & .79 & $.53^{* * *}$ & 1.70 & $-.24^{*}$ & .79 & $.28^{* * *}$ & 1.33 & $-.23^{*}$ & .79 & $.26^{* * *}$ & 1.29 \\
\hline Rc_mi & & & & & $-.56^{* * *}$ & .57 & $.45^{* * *}$ & 1.57 & $-.60^{* * *}$ & .55 & $.35^{* * *}$ & 1.42 & $-.55^{* * *}$ & .58 & $.34^{* * *}$ & 1.40 \\
\hline Rem & & & & & $-.97^{* * *}$ & .38 & $.17^{* * *}$ & 1.19 & $-.81^{* * *}$ & .45 & $-.12^{* * *}$ & .89 & $-.84^{* * *}$ & .43 & $-.24^{* * *}$ & .79 \\
\hline Goal & & & & & .04 & 1.04 & -.04 & .96 & .08 & 1.08 & -.03 & .97 & .05 & 1.05 & -.01 & .99 \\
\hline Intern & & & & & $.76^{* * *}$ & 2.13 & $-.39^{* * *}$ & .68 & $.64^{* * *}$ & 1.90 & .15 & 1.17 & $.41^{* *}$ & 1.50 & $.37^{*}$ & 1.44 \\
\hline Sta & & & & & $.41^{* * *}$ & 1.51 & $-.13^{* * *}$ & .87 & $.48^{* * *}$ & 1.62 & $-.14^{* * *}$ & .87 & $.29^{* * *}$ & 1.34 & $.11^{* * *}$ & 1.12 \\
\hline Pell & & & & & $-.13^{* * *}$ & .87 & $.32^{* * * *}$ & 1.38 & -.09 & .91 & $.19^{* * * *}$ & 1.21 & -.05 & .95 & $.17^{* * *}$ & 1.18 \\
\hline TAP & & & & & $.14^{* * *}$ & 1.15 & $-.59^{* * *}$ & .56 & $.10^{* * *}$ & 1.11 & $-.41^{* * *}$ & .66 & -.04 & .96 & $-.30^{* * *}$ & .74 \\
\hline Hum & & & & & $.23^{* * *}$ & 1.25 & $.24^{* * *}$ & 1.27 & $.25^{* * *}$ & 1.28 & $.21^{* * *}$ & 1.23 & $.33^{* * *}$ & 1.38 & $.17^{* * *}$ & 1.18 \\
\hline STEM & & & & & -.08 & .93 & .02 & 1.02 & -.09 & .91 & -.03 & .97 & -.10 & .90 & -.02 & .98 \\
\hline GPA & & & & & & & & & $.81^{* * *}$ & 2.24 & $-.89^{* * *}$ & .41 & $.70^{* * *}$ & 2.02 & $-.48^{* * *}$ & .62 \\
\hline Cred & & & & & & & & & & & & & $.11^{* * *}$ & 1.11 & $-.14^{* * *}$ & .87 \\
\hline Var Camp & $11^{* * *}$ & & & & $.12^{* * *}$ & & & & $.08^{* * *}$ & & & & $.11^{* * *}$ & & & \\
\hline Var Prog & $12^{* * *}$ & & & & $.11^{* * *}$ & & & & $.08^{* * *}$ & & & & $.10^{* * *}$ & & & \\
\hline LL & $-102,00$ & & & & $-98,417$ & & & & $-85,676$ & & & & $-82,269$ & & & \\
\hline AIC & 204,056 & & & & 196,910 & & & & 171,427 & & & & 164,61 & .90 & & \\
\hline BIC & 204,296 & & & & 197,290 & & & & 171,797 & & & & 164,98 & .60 & & \\
\hline
\end{tabular}


Note. ${ }^{* * *} p<.001,{ }^{* *} p<.05,{ }^{*} p<.01$. Coefficients (Est) represent the change in the baseline logit hazard (log odds) for a unit increase in the predictor's value. The odds ratios (OR) are also given for ease of interpretation. Time intercepts are omitted. The baseline outcome category is "no-event." On = online load, On2 $=$ online load squared, Age $=$ age as of fall 2012, Age2 $=$ age squared, Female $=$ female $($ male $=$ reference), Asian = race Asian, Black = race African American, Hisp = race Hispanic/ Latino, Rc_oth = race other, Rc_mi $=$ race unknown, Rem $=$ remedial, Goal $=$ student goal: transfer or degree, Intern $=$ international student, $\mathrm{Sta}=$ full-time status, Pell $=$ Pell Grant recipient, TAP $=$ recipient of New York State TAP grant, Hum = last program in the humanities, STEM = last program in a STEM field, GPA = GPA in time period, $\mathrm{Cred}=$ credits earned in time period.

Students who were older, male, economically disadvantaged, or from certain ethnic/racial backgrounds were more prone to departure or dropout at any given time, regardless of other factors. Inclusion of semester GPA altered the risk associated with certain demographic predictors in the opposite direction, suggesting a complex dynamic interplay between demographic and academic factors. However, as expected, an upward shift in semester GPA increased the hazard (likelihood) of positive outcomes and decreased the hazard of negative outcomes (see Model 4 in Table 2). In terms of the study's central question, it appears that the curvilinear effect of online course load on dropout/departure can be fully attributed to course completion rates. Interestingly, course completion rates acted as a partial mediator in the relationship between online load and degree completion/transfer. In terms of degree/transfer, when course completion rates were accounted for, an increasing online load was linearly associated with increased likelihood of degree completion/transfer (see Model 5 in Table 2). For a one-unit increase in online load, there was a roughly $72 \%$ increase in the odds of degree or transfer, holding the remaining predictors constant $\left(b_{O n}=.54, \mathrm{OR}=1.72, p=.008\right)$. Holding other predictors at a fixed value, a unit increase in GPA translated into twofold increase $\left(b_{G P A}=.70, \mathrm{OR}=2.02, p<.001\right)$, and a unit increase in credits earned about an $11 \%$ increase $\left(b_{\text {Cred }}=.11\right.$, OR $\left.=1.11, p<.001\right)$ in the odds of degree/transfer.

When it comes to departure or dropout, with credits earned entered as a predictor, the constant effect of online load on prospects of departure/dropout was virtually zero $\left(b_{\mathrm{On}}=0.00, p\right.$ $\left.=.567, b_{\mathrm{On} 2}=.06, p=.091\right)$. Compared to male students and Caucasian students, female students were $10 \%$ and Asian students were $26 \%$ less likely to dropout, respectively. However, the odds for minority students were up to $29 \%$ lower than the odds for Caucasian students.

As expected, the effect of GPA and credits earned on the odds of departure was negative, with a unit increase in both predictors lowering the odds of a negative outcome by $38 \%\left(b_{G P A}=-\right.$ $.48, \mathrm{OR}=.62, p<.001)$ and $23 \%\left(b_{\text {Cred }}=-.14, \mathrm{OR}=.87, p<.001\right)$, respectively. The coefficient for remedial status at Time 1 was negative $(b=-.24, \mathrm{OR}=.79, p<.001)$, suggesting a $21 \%$ lower risk for departure/dropout for remedial students. While counterintuitive, this result is not surprising; if the mission of a community college is to provide a venue for students to compensate for prior academic deficiencies, students in need of remediation should be expected to remain longer in the pipeline. Interestingly, the effect of characteristics such as being an international student, continuously enrolled full-time status, or in a program in the humanities all had a significant positive effect on the two outcomes, a finding implying that outcomes for students with these characteristics tended to occur sooner rather than later. 
To qualify our findings further, we sought to examine whether the effect of online load depended on demographic and academic factors. Therefore, as a follow-up, we probed all twoway and three-way interactions between online load and time-invariant and time-varying covariates in the context of multilevel logistic regressions. That is, the outcomes degree/transfer and departure/dropout were examined one at a time. The outcome variable was recoded in two separate dummy variables as recommended in the literature on competing-risk event-history analysis. Models with interaction terms included were compared using the AIC and BIC test statistics. Table 3 shows the final best-fitting models resulting from these analyses.

Table 3

Two- and Three-Way Interaction Models

\begin{tabular}{|c|c|c|c|c|c|c|}
\hline \multirow{2}{*}{ Predictor } & \multicolumn{3}{|c|}{ Degree/Transfer } & \multicolumn{3}{|c|}{ Departure/Dropout } \\
\hline & Est & SE & OR & Est & SE & OR \\
\hline On & $1.27^{* * *}$ & .24 & 3.54 & $-.34^{* * *}$ & .08 & .71 \\
\hline Age & $-.14^{* * *}$ & .01 & .87 & $.10^{* * *}$ & .01 & 1.11 \\
\hline Age2 & $.00^{* * *}$ & .00 & 1.00 & $-.00^{* * *}$ & .00 & 1.00 \\
\hline Female & $-.06^{*}$ & .03 & .94 & $-.11^{* * *}$ & .02 & .90 \\
\hline White & $.17^{* * *}$ & .03 & 1.19 & .06 & .06 & 1.06 \\
\hline Rem & $-.87^{* * *}$ & .03 & .42 & $-.24^{* * *}$ & .04 & .79 \\
\hline Goal & $.13^{*}$ & .05 & 1.14 & -.05 & .03 & .96 \\
\hline Intern & $.40^{* *}$ & .13 & 1.49 & $.34^{*}$ & .15 & 1.40 \\
\hline Sta & $-.50^{* * *}$ & .15 & .61 & $.11^{* *}$ & .04 & 1.12 \\
\hline Pell & -.06 & .05 & .94 & $.18^{* * *}$ & .03 & 1.20 \\
\hline TAP & -.07 & .04 & .94 & $-.29^{* * *}$ & .04 & .75 \\
\hline Hum & $.35^{* * *}$ & .03 & 1.43 & $.14^{* * *}$ & .03 & 1.15 \\
\hline STEM & $-.14^{*}$ & .06 & .87 & -.07 & .05 & .93 \\
\hline GPA & $.59^{* * *}$ & .04 & 1.80 & $-.48^{* * *}$ & .06 & .62 \\
\hline Cred & $.11^{* * *}$ & .00 & 1.12 & $-.14^{* * *}$ & .01 & .87 \\
\hline On x GPA & $-.35^{* * *}$ & .08 & .71 & $.35^{* * *}$ & .04 & 1.42 \\
\hline On x Sta & $-.92^{* *}$ & .34 & .40 & & & \\
\hline Sta $x$ GPA & $.27^{* * *}$ & .05 & 1.31 & & & \\
\hline On x GPA x Sta & $.42^{* * *}$ & .11 & 1.52 & & & \\
\hline On x White & & & & .04 & .08 & .96 \\
\hline GPA x White & & & & -.04 & .02 & .97 \\
\hline On x GPA x On & & & & $-.09^{* *}$ & .03 & .91 \\
\hline Var Camp & $.13^{* * *}$ & .03 & & $.08^{* * * *}$ & .03 & \\
\hline Var Prog & $.14^{* * *}$ & .02 & & $.09^{* * *}$ & .01 & \\
\hline LL & $-26,478.77$ & & & $-54,048.90$ & & \\
\hline AIC & $53,017.53$ & & & $108,157.80$ & & \\
\hline $\mathrm{BIC}$ & $53,311.86$ & & & $108,454.80$ & & \\
\hline
\end{tabular}

Note. ${ }^{* * *} p<.001,{ }^{* *} p<.05,{ }^{*} p<.01$. Based on results from a multinomial logistic regression with a dichotomous indicator for race and linear specification for online load. Coefficients of time indicators are 
omitted. On $=$ online load, Age $=$ age as of fall 2012, Age2 $=$ age squared, Female $=$ female $($ male $=$ reference), White $=$ race Caucasian $($ minority or other $=$ reference $), \operatorname{Rem}=$ remedial, Goal $=$ student goal: transfer or degree, Intern = international student, $\mathrm{Sta}=$ full-time status, Pell $=$ Pell Grant recipient, TAP $=$ recipient of New York State TAP grant, Hum = last program in the humanities, STEM = last program in a STEM field, GPA= GPA in time period, $\mathrm{Cred}=$ credits earned in time period.

The model specifying a three-way interaction of status, online load, and GPA on degree/transfer and the model with a three-way interaction of online load, GPA, and race on departure/dropout resulted in better model fit by virtue of AIC and BIC criteria. The moderated effects of online load are illustrated in Figures 5 and 6. As seen in Figure 5, the relationship between online load and likelihood of a degree was strongest for the subpopulation of students who maintained full-time status continuously and earned higher grades.

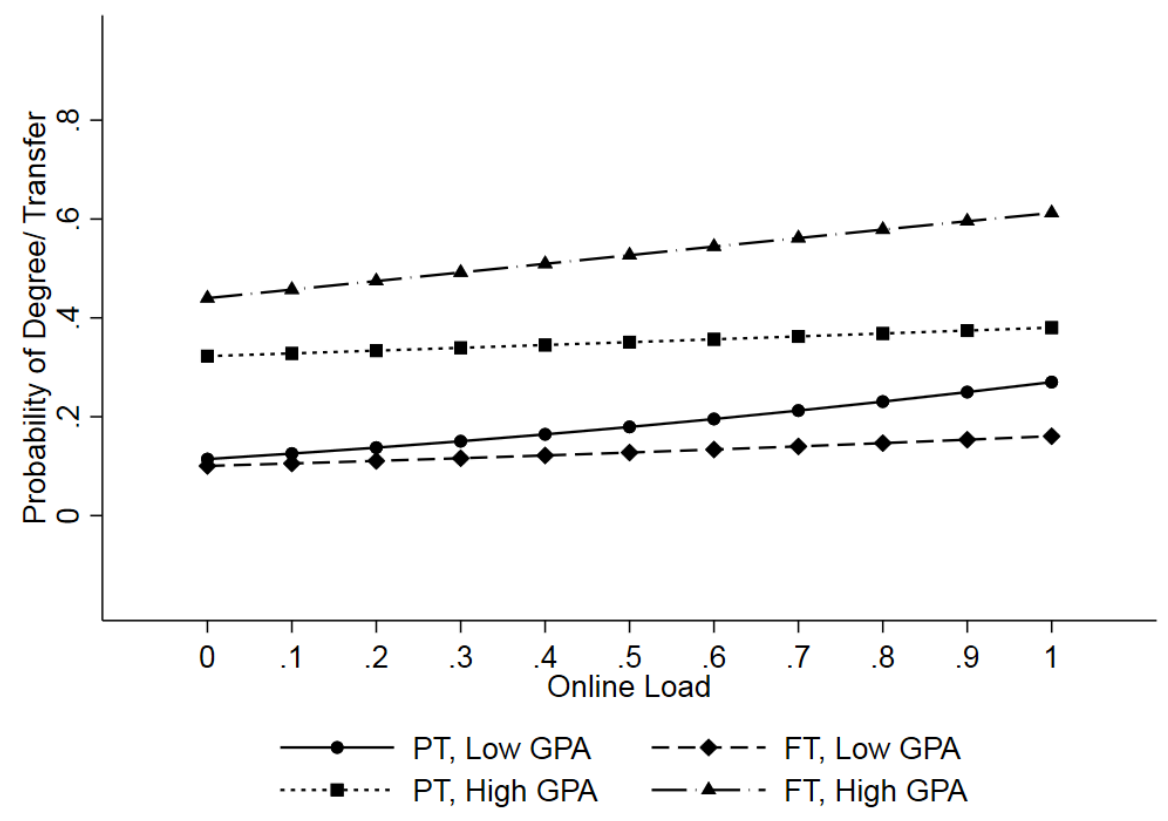

Figure 5. Probability of degree/transfer as a function of online load, GPA, and full-time vs. parttime status. Predicted probabilities for Time 4 at covariate levels: Age $=20.31$, Gender $=$ Male, Race $=$ White, Rem $=$ No, Goal $=$ No, Intern $=$ No, Program $=$ Humanities, Pell $=$ No, TAP $=$ No, Cred $=9.69$.

With respect to the outcome of departure/dropout, the effect of online load was contingent upon GPA in any given time period and race (Caucasian vs. other). As indicated in Figure 6, it appears that online course intensity adversely affected the subpopulation of minority students who were academically stronger; these students were significantly more likely to depart/dropout when the majority of their courses were fully online. 


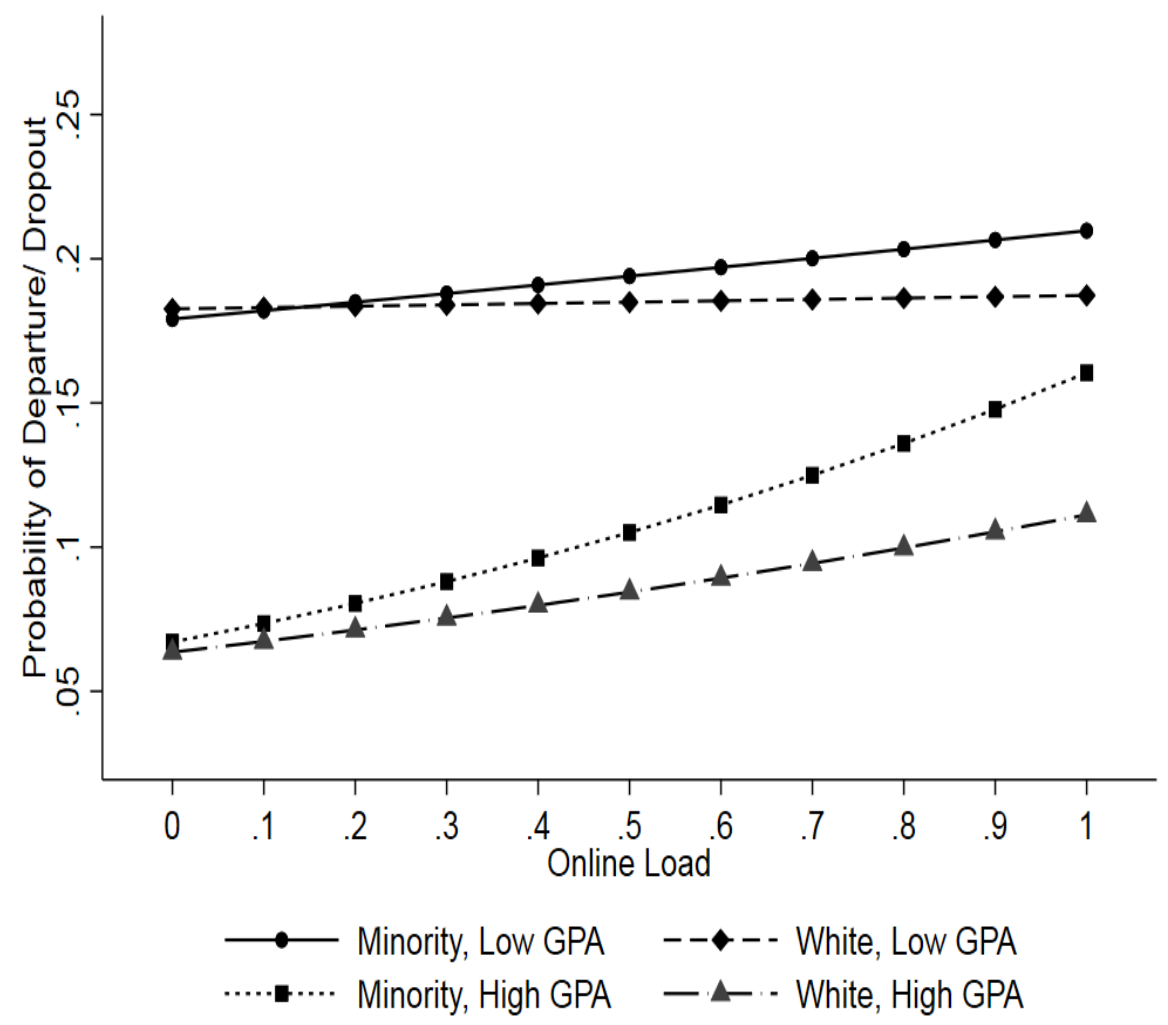

Figure 6. Probability of departure/dropout as a function of online load, GPA, and race. Predicted probabilities for Time 1 at covariate levels: Age $=20.31$, Gender $=$ Male, Status $=$ Part-time, Rem $=$ No, Goal $=$ No, Intern $=$ No, Program $=$ Humanities, Pell $=$ No, TAP $=$ No, Cred = 9.69.

Additional analyses confirmed that in all models the covariates operated in the same manner across time intervals. All analysis suggested, however, an unexplained variation in the hazard for degree completion/transfer and dropout at both program and campus level; variation remained unaccounted for by predictors included in the final model.

\section{Conclusion}

This study attempted to shed light on the potential dynamic links between semester online course intensity and other predictors of college success. We modeled the probability for degree completion, transfer, or departure given both academic and nonacademic factors, including semester online course load. We found that the intensity of online coursework at any given academic term was related to the probability of the concurrent occurrence of transfer, degree completion, and dropout - all in the context of controlling for salient predictors of college success. Adverse outcomes were likely to manifest when students attempted the majority of their semester courses online but failed to accrue credit through these same online courses. However, when controlling for successful course completion, the odds of degree completion increased for each additional unit of successful online study. 
Prior research, including our own, has concluded that online learners in community college settings may be at risk for reduced academic outcomes relative to students who only study in the classroom. These reduced outcomes in prior literature include lower course grades, higher failure rates, increased dropout, and an amplification of known achievement gaps. Our own prior research indicated that under certain conditions (online course loads up to 40\%), online students had better chances of completing a degree. Beyond that tipping point, the enhanced degree-completion rate began to decline rapidly.

The current study provides new insight through an analysis of prior variables while simultaneously considering course completion rates. It appears that online course completion significantly improves the odds of earning a degree. Unlike in previous research (e.g., Shea \& Bidjerano, 2018), in the present study, where course completion rates were accounted for, an increasing online load was linearly associated with increased likelihood of degree completion/transfer. For each additional unit of successful online study, the odds of degree completion increased by 1.72 , holding other predictors constant.

While this is good news for the average online student, as with other research in this area, certain subpopulations were at risk relative to the average. Minority students with higher online loads were more likely to dropout than nonminority students. Of particular concern are minority students who were academically stronger; these students were significantly more likely than nonminority students to drop out when the majority of their courses were fully online. More research is needed using methods that will help us understand why this was the case. Additional student support may be an answer, but first we need to better understand the cause of higher dropout among African American students who were otherwise academically stronger.

A somewhat surprising result can be seen in the interactions between GPA and fulltime/part-time status. The relationship between online load and probability of a degree/transfer was strongest for the subpopulation of students who maintained full-time status continuously and earned higher grades. However, for part-time students with lower GPAs, online course taking improved the upward transfer/degree completion trend relative to their full-time counterparts with low GPAs. This unexpected finding also deserves additional research. 


\section{References}

Seaman, J. E., Allen, I. E., \& Seaman, J. (2018). Grade increase: Tracking distance education in the United States. Retrieved from https://onlinelearningsurvey.com/reports/gradeincrease.pdf

Bettinger, E., Fox, L., Loeb, S., \& Taylor, E. (2017). Changing distributions: How online college classes alter student and professor performance. American Economic Review, 107(9), 2855-2875.

Jaggars, S. S., Edgecombe, N., \& Stacey, G. W. (2013). What we know about online course outcomes: Research overview. New York: Columbia University, Community College Research Center. Retrieved from http://ccrc.tc.columbia.edu/media/k2/attachments/WhatWe-Know-About-Online-Course-Outcomes.pdf

Jaggars, S. S., \& Xu, D. (2010). Online learning in the Virginia Community College system. New York, NY: Columbia University, Teachers College, Community College Research Center.

James, S., Swan, K., \& Daston, C. (2015). Retention, progression and the taking of online courses. Online Learning, 20(2). http://dx.doi.org/10.24059/olj.v20i2.780

Johnson, H., Cuellar Mejia, M., \& Cook, K. (2015). Successful online courses in California's community colleges. San Francisco, CA: Public Policy Institute of California.

Ma, J., Pender, M., \& Welch, M. (2016). Education pays 2016: The benefits of higher education for individuals and society. New York: College Board.

McFarland, J., Hussar, B., de Brey, C., Snyder, T., Wang, X., Wilkinson-Flicker, S., ... Hinz, S. (2017). The condition of education 2017 (NCES 2017-144). U.S. Department of Education. Washington, DC: National Center for Education Statistics. Retrieved from https://nces.ed.gov/pubsearch/pubsinfo.asp?pubid=2017144

Mullin, C. M. (2012). Why access matters: The community college student body (Policy Brief 2012-01PBL). Washington, DC: American Association of Community Colleges.

National Center for Education Statistics. (2011). 2007-08 national postsecondary student aid study (NPSAS: 08). Washington, DC: U.S. Department of Education, Institute for Education Sciences. Retrieved from http://nces.ed.gov/surveys/npsas/

National Center for Educational Statistics. (2017). Number and percentage of students enrolled in degree-granting postsecondary institutions, by distance education participation, location of student, level of enrollment, and control and level of institution: Fall 2014 and fall 2015. Retrieved from https://nces.ed.gov/programs/digest/d16/tables/dt16_311.15.asp 
Scott, M., \& Kennedy, B. (2005). Pitfalls in pathways: Some perspectives on competing risks event history analysis in educational research. Journal of Educational and Behavioral statistics, 30(4), 413-442.

Shea, P., \& Bidjerano, T. (2014). Does online learning impede degree completion? A national study of community college students. Computers \& Education, 75, 103-111.

Shea, P., \& Bidjerano, T. (2016). A national study of differences between distance and nondistance community college students in time to first associate degree attainment, transfer, and dropout. Online Learning, 20(3), 7-19.

Shea, P., \& Bidjerano, T. (2017). Online learning in the 30 community colleges of the State University of New York: Differences in outcomes between classroom and online coursework. In J. Johnston (Ed.), Proceedings of EdMedia: World conference on educational media and technology 2017 (pp. 1192-1198). Waynesville, NC: Association for the Advancement of Computing in Education (AACE).

Shea, P., \& Bidjerano, T. (2018). Online course enrollment in community college and degree completion: The tipping point. The International Review of Research in Open and Distributed Learning, 19(2). http://dx.doi.org/10.19173/irrodl.v19i2.3460

Singer, J. D., \& Willett, J. B. (2003). Applied longitudinal data analysis: Modeling change and event occurrence. New York, NY: Oxford University Press.

Wladis, C., Conway, K., \& Hachey, A. (2016). Assessing readiness for online educationresearch models for identifying students at risk. Online Learning, 20(3). http://dx.doi.org/10.24059/olj.v20i3.980

Xu, D., \& Jaggars, S. S. (2011). Online and hybrid course enrollment and performance in Washington State community and technical colleges (CCRC Working Paper No. 31). New York, NY: Columbia University, Teachers College, Community College Research Center.

Xu, D., \& Jaggars, S. S. (2013). Adaptability to online learning: Differences across types of students and academic subject areas (CCRC Working Paper No. 54). New York, NY: Columbia University, Teachers College, Community College Research Center. 